\title{
Pharmacogenomics
}
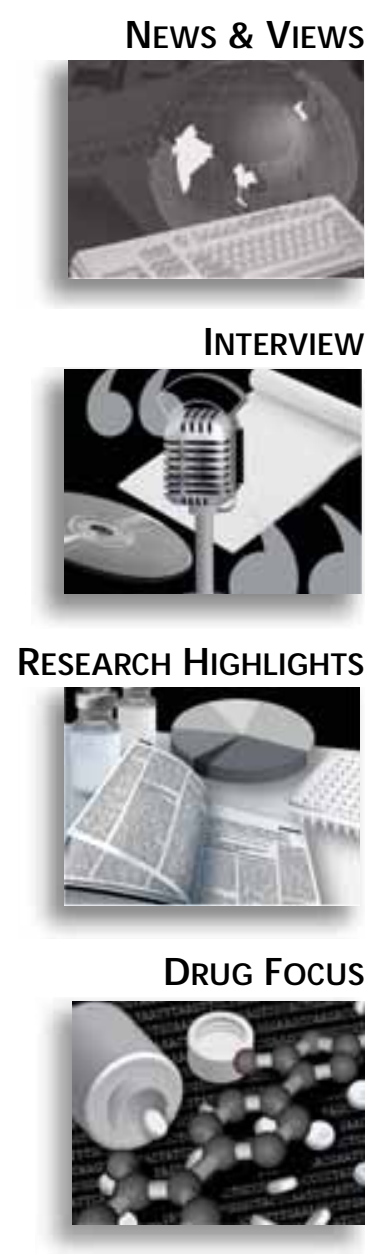

For reprint orders, please contact: reprints@futuremedicine.com

\section{Genetic Information Nondiscrimination Act passed by US senate}

The US Senate passed the Genetic Information Nondiscrimination Act (GINA) by a vote of 95 to 0 on the 24th April, 2008. This act will protect people against any form of discrimination, based on their genetic makeup, from insurance companies and employers. It is hoped that this new legal protection will encourage Americans to use genetic tests as part of their medical care without the fear of being discriminated against.

"D iscrimination based on a person's genetic identity is just as unacceptable as discrimination on the basis of race or religion", exclaimed M assachusetts Democratic Senator Edward Kennedy, calling it the century's first major new civil rights bill.

This much-anticipated and vital measure has been debated in the US Congress for the past 13 years, and will help the promise of personalized medicine be realized as it paves the way for people to take advantage of what personalized medicine can offer, without fear of discrimination.

"We are making a statement and taking a stand, saying as we look to the future that genetic discrimination will not be allowed to flourish, to take root, to stand between Americans and the vast potential that genetic information can provide for a greater quality of life," commented Senator Olympia Snowe, a M aine Republican and chief Senate sponsor.

"I think it will be a very, very strong deterrent against genetic discrimination and will provide remarkable reassurance to a public, who has been quite edgy about this, that it is now safe to find out information about DNA without having it used against you", explained DrFrancis Collins, who heads the US government's National $H$ uman $G$ enome Research Institute.

$\mathrm{H}$ ealth insurers will be prohibited from rejecting coverage of a person or raising premiums for people based on their genetic predisposition to develop a disease. It also bans health insurers from requiring a person to take a genetic test that might reveal a predisposition for illness. Employers, unions and employment agencies will be prohibited from using genetic information in any hiring, firing, compensation or promotion decisions of employees.

Source: Reuters: www.reuters.com 


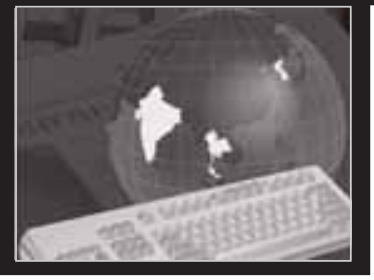

A recent study published in the New Engand Journal of Medione, reveals research that suggests there may be a more effective way to distinguish acute myeloid leukemia (AM L) patients who only need standard therapy for cure from those who require more aggressive treatment to prevent recurrence.

Researchers from the 0 hio State U niversity Comprehensive $C$ ancer $C$ enter $(\mathrm{OH}, \mathrm{USA})$ set out to investigate the role of miRN As in AM L. They studied samples of leukemia cells using miR N A expression profiling, from adults younger than 60 years of age who had cytogenetically normal $A M L$ and highrisk molecular features, which included either an internal tandem duplication in the fms-related tyrosine kinase 3 gene (FLT3-ITD), a wild-type nucleophosmin (N PM 1), or both of them. All the patients had been treated through a clinical trial sponsored by the $C$ ancer and Leukemia Group B (CALGB), a national clinical cooperative group. Analysis of the results obtained associated risk of recurrence with the presence of abnormal levels of seven different families of miR N As.

"This is the first evidence linking changes in levels of miRNAs with the outcome of AM L patients who lack the chromosome abnormalities that we commonly use to predict the cure or relapse of the disease", commented the study's coleader D r G uido M arcucci, associate professor of medicine at O hio State's Comprehensive $\mathrm{C}$ ancer $\mathrm{C}$ enter. "It provides a new tool for a personalized approach to the diagnosis and treatment of cancer".

They also found that high levels of a further six families of miRNAs were associated with an even greater recurrence risk. Furthermore, they discovered that a lower recurrence risk was associated with high levels of members of the miRN A-181 family.

"If validated in a large prospective study, these findings could improve our ability to predict individual patient outcomes and identify the most effective therapy, and lead to new targeted therapies for leukemia," says study leader $\mathrm{Dr}$ Clara D Bloomfield, an international AM L authority at O hio State's Comprehensive $C$ ancer $C$ enter and the W illiam $G$ Pace III Professor of $C$ ancer Research.

Source: Marcucci G, Michael D, Radmacher MD, Maharry $K$ et al.: MicroRNA expression in cytogenetically normal acute myeloid leukemia. N. Engl. J. Med. 358(18), 1919-1928 (2008).

\section{Consortium hopes to create large-scale picture of genetic difference from eight ethnically diverse human genomes}

The U niversity of Washington ( $U W$ ) in Seattle, WA, USA, is leading a nationwide consortium that has just completed the first sequence-based map of structural variations found in the human genome. The project sequenced the genomes of eight people from an ethnically diverse set of backgrounds, which included four individuals of African descent, two of Asian descent, and two of European background. There has not been any previous study that has been conducted as comprehensively as this, which set out to sequence these structural variations in such a systematic approach in multiple individuals.

"T here is a perception that the human genome is essentially completely understood", explained the project's leader,
D r Evan Eichler, UW associate professor of genome sciences and an investigator for the Howard Hughes Medical Institute, M D, USA. "The sequences we have identified range in size from a few thousand to hundreds of thousands of base pairs, and are not part of the published human genome reference sequence. We found that many of these are highly variable in copy and content between individuals. This represents uncharted territory that can now be examined in more detail to determine the function of these new segments of the human genome with respect to disease and gene activity".

A novel 525 segments of DNA were discovered by the researchers that have previously been unknown in the genetics community.
"T he important point here is that we could not have found these differences without sequencing more human genomes from individuals of diverse ancestry to a high-quality standard", explained Eichler.

The authors of the study concluded by stating that their data provides the first high-resolution sequence map of human structural variation, and they suggest that it will become a standard for genotyping platforms and a prelude to future individual genome sequencing projects.

Source: Kidd JM, Cooper GM, Donahue WF et al.: Mapping and sequencing of structural variation from eight human genomes. Nature 453, 56-64 (2008). 


\section{'Genetic $\beta$-blockade' found to improve survival in African-Americans with heart failure}

$\mathrm{N}$ ew findings from a recent study conducted by researchers at the Washington University School of Medicine in St Louis, M O, USA, and collaborating institutions, identified a genetic variant that seems to have a protective effect by prolonging life in approximately $40 \%$ of African-Americans who have suffered from heart failure.

The effect of the genetic polymorphism, found in the GRK5 gene, is similar to that of $\beta$-blockers - drugs that are widely prescribed for heart failure. These new findings also offer a solution as to why $\beta$-blockers have not appeared to have benefited some African-Americans in the past.

"For several years, a controversy has existed in the cardiovascular field because of conflicting reports about whether $\beta$-blockers helped African-American patients", commented the lead author Gerald W Dorn II, $M D$, professor of medicine, associate chairman for translational research and director of the Center for Pharmacogenomics at Washington U niversity. "By mimicking the effect of $\beta$-blockers, the genetic variant makes it appear as if $\beta$-blockers aren't effective in these patients" explained Dorn. "But although $\beta$-blockers have no additional ben efit in heart failure patients with the variant, they are equally effective in

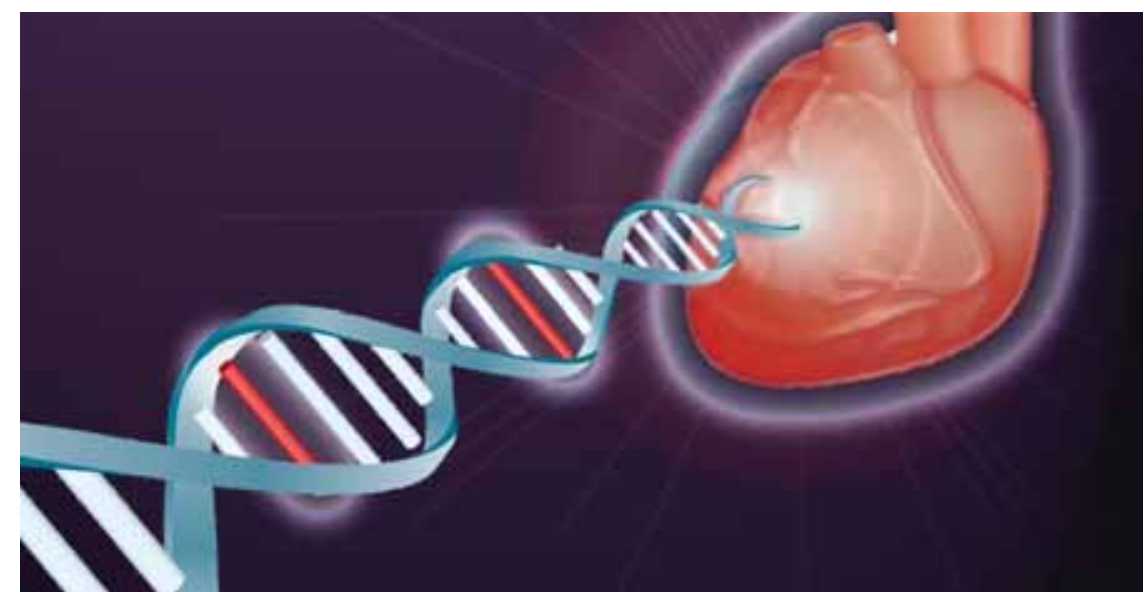

Caucasian and African-American patients without the variant".

The standard therapy for cardiac failure and ischemia $b$ is $\beta$-adrenergic receptor ( $\beta$-AR) blockade. In this study, the researchers set out to sequence two genes, GRK2 and GRK5 that are involved in desensitizing $\beta$-ARs, since it has been suggested that genetic GRK variants might modify outcomes in these syndromes. They sequenced these genes in a cohort of 96 people of European-American, African-American or Chinese descent to look for any new variation that may occur between them. For the most part, they found that gene sequences in GRK2 or GRK5 were exactly the same in all people. H owever, there was an exception. There was one common variation found to occur in more than $40 \%$ of African-Americans, called the GRK5-LeA41 variant.

The researchers then carried out human association studies and the results showed that there was a pharmacogenomic interaction between the GRK5-LeA41 variant and $\beta$-blocker treatment - where the presence of the GRK5-LeAAl polymorphism was associated with a decreased mortality in African-Americans with heart failure or cardiac ischemia. They also found that in 375 prospectively followed African-American subjects with heart failure, the GRK5Lex11 variant protected against death or cardiac transplantation.

"These results offer an explanation for the confusion that has occurred in this area since clinical trials of $\beta$-blockers began", remarked Dorn. "Our study demonstrates a mechanism that should lay to rest the question about whether $\beta$-blockers are effective in African-Americans - they absolutely are in those who don't have this genetic variant".

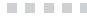

Source: Liggett SB, Cresci S, Kelly RJ et al.: A GRK5 polymorphism that inhibits $\beta$-adrenergic receptor signaling is protective in heart failure. Nat. Med. (2008) (Epub ahead of print). 